\title{
Türkiye'de İnşaat Sektöründe Çalışan Mimar ve İnşaat Mühendislerinin Cam Tavan Algılarının Erillik/Dișillik Kültür Boyutu Açısından Belirlenmesi
}

\author{
Hava Yaşbay Kobal ${ }^{1 *}$, İlhami Ay ${ }^{2}$ \\ 1* Hakkâri Üniversitesi, İktisadi ve İdari Bilimler Fakültesi, İşletme Bölümü, Hakkâri, Türkiye, (ORCID: 0000-0002-2589-785X), havayasbay@hakkari.edu.tr \\ ${ }^{2}$ Hakkâri Üniversitesi, Çölemerik Meslek Yüksekokulu, Mimarlık ve Şehir Planlama Bölümü, Hakkâri, Türkiye (ORCID: 0000-0002-3506-3234), \\ ilhamiay@hakkari.edu.tr
}

(İlk Geliş Tarihi 31 Mayıs 2021 ve Kabul Tarihi 15 Ağustos 2021)

(DOI: 10.31590/ejosat.945932)

ATIF/REFERENCE: Yaşbay Kobal, H. \& Ay, İ. (2021). Türkiye'de İnşaat Sektöründe Çalışan Mimar ve İnşaat Mühendislerinin Cam Tavan Algılarının Erillik/Dişillik Kültür Boyutu Açısından Belirlenmesi. Avrupa Bilim ve Teknoloji Dergisi, (27), 95-102.

$\ddot{O} \mathbf{z}$

Bu çalışmanın amacı, Türkiye'de inşaat sektöründe çalışan mimar ve inşaat mühendislerinin cam tavan algılarının erillik/dişillik kültür boyutu algıları açısından belirlenmesidir. Anket yöntemi ile toplanan veriler SPSS 25 nicel analiz programı ile analize tabi tutulmuştur. Analiz sonucunda, mimarların ve inşaat mühendislerinin cam tavan algılarının oluşmasında etkili olan toplumsal (stereotipler ve mesleki ayrım) ve bireysel engeller (çoklu rol üstlenme) boyutlarının kadınlarda; örgütsel engeller (örgütsel kültür ve politikalar, informal ağları kullanmama) boyutunun erkeklerde daha yüksek olduğu saptanmıştır. Anketi cevaplayanların eril kültür algıları erkeklerde daha yüksektir. Diğer taraftan anketi cevaplayanların mimar veya inşaat mühendisi olmalarının cam tavan ve erillik kültür boyutu algıları açısından bir farklılık ortaya çıkarmadığı saptanmıştır. Son olarak eril kültür algısı arttıkça cam tavanın boyutlarından biri olan toplumsal engeller algısının artacağı saptanmıştır.

Anahtar Kelimeler: Cam Tavan, Erillik/Dişillik, Toplumsal Roller.

\section{Determination of Glass Ceiling Perceptions Of Architects And Civil Engineers Working In The Turkish Construction Sector In Terms Of The Dimension Of Masculinity/Femininity Culture}

\begin{abstract}
This study aims to to determine the perception of glass ceiling of architects and civil engineers working in the Turkey construction industry in terms of masculinity / feminine culture dimension perceptions. The data collected by the questionnaire method were analyzed with the SPSS 25 quantitative analysis program. As a result of the analysis it was found that social (stereotypes and occupational distinction) and individual barriers (taking on multiple roles) dimensions that are effective in the formation of glass ceiling perceptions of architects and civil engineers; The dimension of organizational barriers (organizational culture and policies, not using informal networks) was found to be higher in males. The perceptions of masculine culture of the respondents are higher in men. On the other hand, it was determined that the respondents' perceptions of the glass ceiling and masculinity cultural dimension did not differ in terms of being architects or civil engineers. Finally, It has been determined that as the perception of masculine culture increases, the perception of social obstacles, one of the dimensions of the glass ceiling, will increase.
\end{abstract}

Keywords: Glass Ceiling, Masculinity/ femininity, Social Roles 


\section{Giriş}

1970'lerden beri kadınların işgücüne katılım oranı artmasına (Dimovski vd., 2010:61) rağmen, üst yönetim kademelerindeki oranı düşük kalmıştır (Linehan, 2002:802; Dreher, 2003:541542; Weyer, 2006: 441; Jawahar ve Hemmasi, 2006: 643; Bendl ve Schmidt, 2010:614; Sabat ve Mishra, 2010:365; Whang ve Cho, 2013:43; Downes vd., 2014: 131). Kadın yöneticiler, kariyer geliştirme ve üst yönetime terfi için erkeklerden daha az firsatlara sahip olduklarını ifade etmektedirler. Chenevert ve Tremblay (2002:920) ile Meyerson ve Fletcher (2000:127), kadın yöneticilerin yüksek eğitim düzeyine ve kariyerlerinde ilerleme arzusuna sahip olsalar bile, çok azının erkek meslektaşları ile aynı statüyü elde etmelerinin söz konusu olduğunu ve bunun sebeplerinden birinin de "cam tavan" olduğunu ifade etmişlerdir (Dimovski vd., 2010:62).

Alan yazında cam tavan araştırmaları büyük oranda cam tavanın örgütlerde var olup olmadığı, cam tavan engelleri ve bu engelleri ortadan kaldırmak için hangi stratejilerin uygulanması gerektiğine odaklanılmıştır. Cam tavan olgusunun erkek egemen olarak kabul edilen çeşitli meslek grupları açısından ele alınması bir başka araştırma alanıdır (Sökmen ve Şahingöz, 2017:113). Toplumun kadına biçtiği cinsiyet rolleri nedeniyle kadınlar iş hayatında erkeklerin gerisinde kalabilmektedir. Çünkü toplumda erkeklere iktidar ve mücadeleyi içine alan roller verilirken kadınlara ev içi roller verilmiştir. Bu roller ile paralel şekilde meslekler cinsiyetlere göre sinıflandırılmakta; bazı meslekler kadın mesleği, bazıları da erkek mesleği olarak görülmektedir. Buradan hareketle araştırmanın amacı, Türkiye'de inşaat sektöründe çalışan mimar ve inşaat mühendislerinin cam tavan algılarının erillik kültür boyutu özellikleri açısından belirlenmesidir.

\subsection{Cam Tavan Kavramı}

"Cam tavan" kavramını ilk kez 1986 yılında Hymowitz ve Schellhardt, Wall Street Journal'da yer alan raporda kullanmışlardır (Lockwood, 2004:1; Roman, 2017:1 Lathabhavan, 2019:305). Cam tavan, kadınların ve azınlık grupların örgütlerde üst düzey yönetici pozisyonlarına ilerlemesini ve tam potansiyellerine ulaşmalarını engelleyen görünmez fakat güçlü engelleri ifade etmektedir (Cannings, 1988; 87; Knutson ve Schmidgall, 1999:64; Murrell ve James, 2001: 244; Jackson, 2001: 30; Lockwood, 2004:1; MathurHelm, 2006:311; Weyer, 2006: 442; Hu ve Myeong-Su, 2008:1; Downes vd., 2014: 132; Lathabhavan, 2019:305). Bu engel, performansın doğru bir ölçüsü olarak iş ile ilgili becerilere, eğitime veya deneyime sahip olmadıkları için değil, sadece kadın ya da azınlık oldukları gerçeğine dayanan bir engeldir (Cannings, 1988; 87; Stroh vd., 1996:102-103; Goodman vd., 2003: 475-476).

Örgütlerde 'cam tavan' olgusu üç nedenden dolayı problemler yaratmaktadır. İlk olarak alt ve orta düzey yönetim pozisyonlarında yer alan, örgüte özgü değerli bilgilere sahip ve yeteneklerinden yararlanılabilecek kadın yöneticiler cam tavan nedeniyle üst yönetime ulaşma firsatının sınırlı olduğunu algıladıklarında motivasyonları azalabilir ve işten ayrılmak isteyebilirler. İkincisi, üst yönetim üyeleri arasındaki çeşitlilik eksikliğiyle ilgilidir. Fazla homojenlik kötü ve maliyetli kararlara yol açabilir. Üçüncüsü, zorlu işgücü piyasasında cinsiyet kaynaklı engeller ihtiyaç duyulan kaynakların ve yeteneklerin arzını azaltabilir. Son olarak cam tavanı sürdürmek, örgütün çalışanlarına nasıl davrandığ ${ }_{1}$ konusunda hem erkeklerin hem de kadınların görüşlerini etkileyebilir ve yetenekli insanların gelecekteki firsatları sorgulamasına yol açabilir (Dreher, 2003: 541-542; Goodman, 2003:476).

\subsection{Cam Tavan Engelleri}

Cam tavan engelleri literatürde bireysel kaynaklı, örgütsel kaynaklı ve toplumsal kaynaklı engeller olarak ele alınmaktadır. Bireysel kaynaklı engellerden biri olan çoklu rol üstlenme; "kadının hem anne hem eş hem birey ve hem de çalışan olarak birçok role sahip olması" anlamına gelmektedir (Korkmaz, 2014:10; 2016: 106). Bu nedenle, birçok kadın kurumsal merdiveni ilerletme olasılığını artıracak adımlar atmak için dezavantajlıdır (Lockwood, 2004:3). Bireysel kaynaklı bir diğer cam tavan engeli bireysel tercih ve algıdır. Kadınların alt düzey pozisyonların çoğunu oluşturduğu örgütlerde sahip oldukları cinsiyet özelliği örgütün başarı gereksinimleri ile tutarsız olarak algılanmaktadır. Kadınlar da olumsuz değerlendirmeleri ve klişeleri içselleştirebilir ve başarılı olamayacakları korkusuyla ilerleme firsatlarını geri çevirebilirler (Foley vd., 2001:471-472; Downes vd., 2014: 133). Ayrica kalıp yargılar nedeni ile de kadınlar, erkek gibi kadın olarak anılmak istemedikleri için yöneticilik görevini geri çevirebilirler (Karcıŏlu ve Leblebici, 2014:6). Örgütsel kaynaklı engeller; örgüt kültürü, örgüt politikası, mentor eksikliği ve informal ağları kullanmama olarak sıralanabilir. Örgütlerde, üst yönetim pozisyonuna gelebilmek için kişinin özel hayatını feda etmesi gerektiği vurgulandığı sürece, kadınlar bu pozisyonlarda azınlık olarak kalacaktır (Van Vianen ve Fischer, 2002:334). Örneğin çeşitliliğe gösterilen sınırlı ilgi ve hoşgörü, kadınlar için dışlayıcı bir ortama dönebilir (Dimovski vd., 2010:63) ya da erkekleri kurumsal güç pozisyonlarında tutabilir (Lockwood, 2004:2). Dolayısıyla cam tavanın bir başka göstergesi, kadınların ilerlemesinin örgüt kültürü tarafından engellenmesidir (Lockwood, 2004:2; Dimovski vd., 2010:62-63). Örgüt politikası, çalışanlara rehberlik eden ilkeler bütünüdür. Kadınlar toplumsal önyargılar sebebi ile iş başvurularında erkek adaylara göre farklı koşullara tabi tutulabilmektedir. Ayrıca, örgütlerin, performans değerlendirme ve ücret politikaları da kadınlar aleyhine eşitsiz uygulanabilmektedir. Bu tür uygulamaların her biri kadınlar için bir cam tavan engelidir (Karcıoğlu ve Leblebici, 2014:6). Etkili bir mentora sahip olmak özellikle yüksek yönetim statüsüne sahip kadınların ilerlemesinde yardımcı olan önemli bir stratejidir (Lewis ve Fagenson, 1995: 46; Ragins vd., 1998: 32; Knutson ve Schmidgall, 1999:65; Sabat ve Mishra, 2010:369). Ancak, mentor bulmak genellikle zor bir iştir. Örgüt kültürü genellikle gayri resmi mentorluk ilişkilerine elverişli değildir (Lewis ve Fagenson, 1995: 46). Bu durum da cam tavan sendromuna neden olan bir engel olarak ortaya çıkmaktadır. Örgütsel kaynaklı engellerin sonuncusu olarak kadınların, erkeklerin örgütte iş ilişkileri geliştirmek için kullandıkları gayri resmi ağlara erişime sahip olmaması ve bu ağlardan dışlanmasıdır (Knutson ve Schmidgall, 1999:67; Lockwood, 2004:3). Toplumsal kaynaklı engeller mesleki ayrım ve stereotiplerdir. Toplumsal birtakım önyargılar nedeniyle meslekler cinsiyetlere göre ayrışmakta; bazı meslekler kadın, bazıları da erkek mesleği olarak görülmektedir. Örneğin; tamircilik, genel müdürlük, müfettişlik vb. işler erkek işleri olarak; hemşirelik, sekreterlik gibi işler ise kadın işleri olarak sınıflandırılmaktadır. Bu nedenle kadınlar, erkek meslekleri olarak görülen işlerde daha az tercih edilmektedirler (Karcıŏlu ve Leblebici, 2014:7-8). Stereotipler (önyargılar), algılayıcının bazı gruplar hakkındaki bilgi, inanç ve beklentilerini içeren bilişsel yapılardır. Çoğu erkek, kadınların liderlik pozisyonları 
için kendilerinden daha az yetkin veya daha az uygun olduğunu varsaydiğından, cinsiyete yönelik stereotipler en yaygın diş engeldir (Sabat ve Mishra, 2010:369). Cinsiyete yönelik stereotiplerde kadınlar erkeklerden daha pasif, uyumlu, duygusal, şefkatli ve bağımlı; erkekler ise daha hırslı, agresif, kendine güvenen, güçlü ve bağımsı bireyler olarak algilanmaktadır (Kelly vd., 1993:23; Williams vd. 1999: 513514; 23; Rudman ve Phelan, 2008: 62-64; Smith vd., 2012:1). Kadınlar hakkında stereotipler kadının çalışma hayatına ket vurduğu gibi, kadınların yöneticilik rolleri için uygun olabileceği düşüncesini de engellemektedir (Korkmaz, 2014: 10; 2016:107).

\subsection{Cam Tavan Nedenleri ve Sonuçları}

Boone vd. (2013:230), küresel endüstri lideri şirket yöneticileri ile cam tavan engelleri üzerine bir araştırma yapmışlardır. Araştırma sonucunda en yaygın bireysel engellerin iş yaşamı dengesi; iş yeri engellerinin ise mentor eksikliği, kariyer planlamasının olmaması, stereotipler olduğu sonucuna ulaşmışlardır (Boone vd., 2013:230). Dimovski vd. (2010), Singapurlu ve Malezyalı orta düzey kadın yöneticilerden oluşan bir örneklemde cam tavan engellerini araştırmıştır. Örgütlerin kültürü kadın yöneticilerin terfisini engellemekte ve kadın yöneticiler ağ oluşturma, mentorluk gibi kariyer gelişimi için gerekli firsatlara sahip olamamaktadırlar (Dimovski vd., 2010:61). Mathur-Helm (2006: 311), Güney Afrika'nın dört büyük perakende bankasındaki cam tavan olgusunun gerçekliğini incelemiştir. Sonuçlar, cam tavanın gerçek olduğunu ve üst yönetim kademelerinde yer alan kadın sayısının az olduğunu göstermektedir.

Cam tavan, örgütlerdeki çalışanların iş tatminini etkilemektedir. Örgütte yüksek seviyeli cam tavanla karşılaşan kadın çalışanlar, performanslarının karşılığını alamadıklarını düşünmekte ve iş tatminleri azalmaktadır (Khan vd., 2012: 59). Balasubramanian ve Lathabhavan (2018:72) kadın çalışanlarda cam tavan inançları ile iş tatmini arasındaki ilişkiyi, işe bağlılığın aracılık rolü aracılığıyla incelemişlerdir. Cam tavan inançları ile iş tatmini arasındaki ilişkide işe bağlılığın aracı rolü olduğu tespit edilmiştir.

Örgütlerde alt düzeydeki kadın yöneticiler cinsiyet nedeniyle üst yönetime ulaşma firsatının sınırlı olduğunu algıladıklarında (Dreher, 2003: 542) ya da erkek meslektaşlarına yönelik terfi kararları verildiğinde motivasyonlarını kaybedebilirler (Luksyte ve Spitzmueller, 2011: 258). Channar (2011:177), sağlık kurumlarında cinsiyet ayrımcılığının örgütsel sonuçlarını araştırmıştır. Sonuçlar, cinsiyet ayrımcılığının çalışanların motivasyonunu, örgüte bağlılığını azalttığını; stres düzeyini artırdığını göstermektedir.

\subsection{Erillik / Dişillik}

Kadınlarla erkekler arasındaki biyolojik farklar dünyanın çoğu yerinde aynıdır. Fakat kadınların ve erkeklerin toplumsal rollerinin sadece bir k1smı biyolojik kisitlamalarla belirlenebilmektedir ve toplumlara özgüdür (Hofstede vd. 2010: 137). Hofstede bu farklılıkları toplumlar açısında "erillik" ve "dişillik" olarak isimlendirmiştir. Hangi davranışların herhangi bir cinsiyete ait olduğu bir toplumdan diğerine farklılık göstermektedir.

Hofstede (2010: 139), toplumların hangi kriterlere göre eril ya da dişil sayılacağını belirleyebilmek için aşağıdaki öğeleri tanımlamıştır.

Eril kutup için:
- Kazanç: yüksek kazanç elde etmek için bir firsata sahip olmak

- Tanınma: İyi bir iş yapıldığında hak edilen takdiri almak

- İlerleme: daha üst düzey işlere ilerleme firsatına sahip olmak

- Zorluk: kişisel bir başarı duygusu edinilebilecek zorlu bir iş yapmak

Dişil kutup için (Hofstede vd. 2010: 139):

- Yönetici: Amirle iyi bir çalışma ilişkisine sahip olmak

- İş birliği: Birbirleriyle iyi iş birliği yapan insanlarla çalışmak

- Yaşam alanı: Kişinin kendisi ve ailesi için arzu edilen bir alanda yaşaması

- İstihdam Güvenliği: Kişinin istediği sürece çalışabileceği güvenceye sahip bir işinin olması

Eril toplumlarda; atılganlık, rekabet, maddi kazanç gibi değerlere önem verilmektedir. Bu kültürlerde para kazanmak, başarı ve yüksek performans önemli değerlerdir. Dişil kültürlerde ise daha 1lımlı ve duyarlı olmak, merhametli olmak, insan ilişkilerine paradan çok önem vermek, diğer insanlara yardım etmek baskın değerlerdir (Hofstede, 1980b: 42-63; Hofstede, 1991: 43).

Toplumsal hayatta kadının yapamayacağı işler ve dolayısıyla gerçekleştiremeyeceği roller olduğu kabul edilmektedir (Güney, 2012: 178). Erkeklerin ve kadınların belirli mesleklere göre dağılımında da bu toplumsal rol beklentileri hakimdir. Eril kültürlerde farklı cinsiyetler için farklı roller öngörülmekteyken, dişil kültürlerde cinsiyet rollerinin birbirine daha yakın olduğu bilinmektedir (Erkenekli, 2014: 578). Örneğin, dişil toplumlarda bir kadının kamyon şoförü veya hukukçu olması, bir erkeğin de balet veya ev erkeği olması normal karşılanabilmektedir. Buna göre, kadınlar Rusya'da doktor, Belçika'da diş hekimi ve Batı Afrika'nın bazı bölgelerinde esnaf olabilmektedir. Eril kültüre sahip olan toplumlarda ise, kadın ve erkek rolleri arasında kesin bir ayrım yapılmaktadır (Hofstede 1991a: 85). Kadın yöneticiler Japonya'da yok denecek kadar azdır (Hofstede 2010: 137-138).

Kadınlar çalışma yaşamında birtakım engellerle karşılaşabilmektedir. $\mathrm{Bu}$ engeller, kadınların toplumsal rolleri bu rollere uygun beklentilerle iş yaşamının bağdaşmaması, belirli mesleklerin kadınlara kapalı olması, iş yaşamında yükselmelerinin engellenmesi olarak sıralanabilir (Gelegen, 2001: 27). Dolayısıyla eril değerleri yüksek olan toplumlarda kadınlar kariyer hayatlarında engellenebilir, onların yaptığı işler daha değersiz olarak görülebilir. Eşit olmayan istihdam uygulamaları söz konusudur. Dişil toplumlarda kadınlar da erkeklerin çalıştığı işlerde çalışabilir (Altay, 2006: 36).

\subsection{Cam Tavan Algısı ve Erillik - Dişillik}

Kadınların kariyerlerinin önündeki kurumsal engellerle ilgili söylemlerde erkek egemen bir kültüre atıfta bulunulmaktadır. Üst düzey yöneticilerin büyük çoğunluğunun erkek olması, örgüt kültürlerinin hala erkek egemen norm ve değerlerin hakimiyetinde olduğu iddia edilmiştir. Bu erkeksi kültürler, cam tavanın temel unsurlarından birini oluşturmaktadır (VanVianen ve Fischer, 2002:316). 
VanVianen ve Fischer (2002:316), üst yönetimde kariyer yapmak için kadınların güdülerini araştıran iki çalışma yapmıştır. Çalışmaların ana hipotezi, kadınların erkeklere kıyasla kültür tercihleri nedeniyle yönetim pozisyonlarına, özellikle üst yönetim pozisyonlarına daha az ilgi duyacakları şeklindedir. Birinci çalışmanın amacı $(N=327)$, yönetim pozisyonlarındaki çalışanların kültür tercihlerinin yönetici olmayanlara göre daha erkeksi olacağı yönündeki varsayımı test etmekti. Sonuçlar, cinsiyet farklılıklarının sadece yönetici olmayan gruplarda olduğunu, kadınların erkeklerden daha az erkeksi kültür tercihleri olduğunu göstermiştir. Yöneticiler, geleneksel erkeksi rekabet, çaba ve iş baskısı değerlerini, bir yönetim pozisyonu işgal etmeyen çalışanlardan daha önemli olarak değerlendirmiştir. Her iki çalışmada da, tüm örgüt düzeylerinde çalışanlar tarafından dişil örgütsel değerlerin eril değerlere tercih edildiği saptanmıştır. $\mathrm{Bu}$, yönetim seviyelerindeki bireylerin ağırlıklı olarak eril değerlere bağlı kaldığına dair yaygın görüşle çelişmektedir. İkinci çalışmada $(\mathrm{N}=350)$, kültür tercihlerinin, yönetici olmayanların ve orta düzey yöneticilerin bir devlet kurumunda üst yönetim düzeyinde bir kariyer peşinde koşma istekleri üzerindeki etkileri incelenmiştir. Sonuçlar, örgütsel kültür tercihlerinin yönetici olmayan çalışanların hırsları için öngörücü olduğunu, ancak orta düzey yöneticilerin tutkusu için öngörücü olmadığını göstermiştir. Genel olarak, kadınlar erkeklerden daha az hırslıydı ve hırslı kadınlar bile iş-ev çatışmasını kariyer gelişiminin önünde önemli bir engel olarak algılamışlardır (Van Vianen ve Fischer, 2002:316,332).

\section{Materyal ve Metot}

Bu araştırmanın amacı, Türkiye'de inşaat sektöründe çalışan mimar ve inşaat mühendislerinin cam tavan algılarının erillik/dişillik kültür boyutu özellikleri açısından belirlenmesidir. Araştırma, mevcut durumu ortaya koyması bakımından, tanımsal türde nitelendirilebilir. Ülkemizin lokomotif sektörlerinden biri olan inşaat sektöründe çalışan mimar ve mühendislerin mesleki ayrıma maruz kalabilecek meslek gruplarından olduğu düşünülmektedir. Çünkü inşaat sektöründe hem kadın çalışan sayısı azdır hem de daha düşük pozisyonlarda çalıştırılmaktadır. Bu nedenle araştırmanın ana kütlesini Türkiye'de özel sektörde çalışan mimar ve inşaat mühendisleri oluşturmaktadır. Örneklemede tesadüfi olmayan örnekleme yöntemlerinden kolayda örnekleme yöntemi tercih edilmiştir. Bu kapsamda, Mart 2021'de özel sektörde çalışan 122 mimar ve inşaat mühendisinden anket yöntemiyle veri toplanmıştır. Küresel pandemi koşulları nedeniyle yüz yüze anket toplamak mümkün olmadığından veriler, yine nicel bir yöntem olan, online anket yöntemiyle toplanmıştır. Veri toplama araçları olarak ölçeği ile demografik sorular kullanılmıştır. Örgütsel kültür ve örgütsel bağlılık 5'li Likert tipi ölçekle ölçülmeye çalışılmıştır. Veri analizinde kullanılan istatistiksel yöntemler; frekans dağılımları, güvenilirlik analizi, tek yönlü varyans analizi (ANOVA testi), bağımsız gruplar $t$ testi ve Pearson Korelasyon analizidir. Araştırma kapsamında test edilen hipotezler şunlardır:

$\mathrm{H}_{1}$ : İnşaat mühendisleri ve mimarların cam tavan algıları cinsiyete göre anlamlı bir farklılık göstermektedir.

$\mathrm{H}_{2}$ : İnşaat mühendisleri ve mimarların cam tavan algıları mesleğe göre anlamlı bir farklılık göstermektedir.

$\mathrm{H}_{3}$ : İnşaat mühendisleri ve mimarların erillik kültür özellikleri cinsiyete göre anlamlı bir farklılık göstermektedir.
$\mathrm{H}_{4}$ : İnşaat mühendisleri ve mimarların erillik kültür özellikleri mesleğe göre anlamlı bir farklılık göstermektedir.

$\mathrm{H}_{5}$ : İnşaat mühendisleri ve mimarların cam tavan algısı ile erillik kültür özellikleri arasında pozitif yönlü ve anlamlı bir ilişki vardır.

\section{Araştırma Sonuçları ve Tartışma}

Anketi cevaplayanların demografik yapılarını ortaya koymak üzere frekans dağılımları incelenmiştir. Sonuçlar Tablo 1'deki gibidir.

Tablo 1. Katılımcıların Demografik Özelliklere Göre Dă̆ılımı

\begin{tabular}{|c|l|c|c|}
\hline \multicolumn{2}{|c|}{} & Frekans & Yüzde \\
\hline \hline \multirow{2}{*}{ Cinsiyet } & Kadın & 73 & 59,8 \\
& Erkek & 49 & 40,2 \\
\hline \multirow{4}{*}{ Yaş } & 18-25 yaş aras1 & 31 & 25,4 \\
& 26-35 yaş aras1 & 54 & 44,3 \\
& 36-45 yaş aras1 & 30 & 24,6 \\
& 46-55 yaş aras1 & 6 & 4,9 \\
& 66 yaş ve üzeri & 1 & 0,8 \\
\hline \multirow{2}{*}{ Öğrenim } & Lisans & 83 & 68 \\
& Yüksek Lisans & 31 & 25,4 \\
Meslek & Doktora & 8 & 6,6 \\
\hline \multirow{3}{*}{ Aylık Gelir } & Mimar & 68 & 55,7 \\
& İnşaat Mühendisi & 54 & 44,3 \\
\hline & $0-2.000$ TL & 15 & 12,3 \\
& 2.001-4.000 TL & 42 & 34,4 \\
& $4.001-6.000$ TL & 15 & 12,3 \\
& 6.001-8.000 TL & 25 & 20,5 \\
& 8.001-10.000 TL & 12 & 9,8 \\
& 10.001 TL ve üzeri & 13 & 10,7 \\
\hline
\end{tabular}

Tablo 1'de görüldüğü üzere, katılımcıların \%59,8'i (73 kişi) kadın, \%40,2'si (49 kişi) erkek; \%25,4'ü (31 kişi) 18-25 yaş aralığında, \%44,3'ü (54 kişi) 26-35 yaş aralığında, \%24,6'sı (30 kişi) 36-45 yaş aralığında, \%4,9'u (6 kişi) 46-55 yaş aralığında, $\% 0,8$ 'i (1 kişi) 66 yaş ve üzeri yaş aralığında; \%68'i (83 kişi) lisans mezunu, \%25,4'ü (31 kişi) yüksek lisans mezunu, \%6,6's1 (8 kişi) doktora mezunu; \%55,7'si mimar, \%44,3'ü (54 kişi) inşaat mühendisi; \%12,3'ü (15 kişi) 0-2.000 TL, \%34,4'ü (42 kişi) 2.001-4.000 TL, \%12,3’ய̈ (15 kişi) 4.001-6.000 TL, \%20,5'i (25 kişi) 6.001-8.0000 TL, \%9,8'i (12 kişi) 8.00110.000 TL ve $\% 10,7$ 'si (13 kişi) 10.001 TL ve üzeri aylık gelire sahiplerdir.

Cam tavan algısının alt boyutlarını belirlemek üzere keşfedici faktör analizi uygulanmıştır. Faktör analizinde temel bileşenler yöntemi ve varimax döndürme yöntemi kullanılmıştır. Alt boyutların güvenilirlikleri Alpha metoduyla ölçülmüştür. Analiz sonuçları Tablo 2'de görülmektedir. 
Tablo 2. Cam Tavan Algısına İlişkin Keșfedici Faktör ve Güvenilirlik Analizi

\begin{tabular}{|c|c|c|c|c|}
\hline Faktör & İfade & $\begin{array}{l}\text { Faktör } \\
\text { Yükü }\end{array}$ & $\begin{array}{l}\text { Açıklanan } \\
\text { Varyans }\end{array}$ & $\begin{array}{l}\text { Güvenilirlik } \\
\text { Katsayıs1 }\end{array}$ \\
\hline \multirow{8}{*}{$\begin{array}{l}\text { Toplumsal } \\
\text { Engeller } \\
\text { (Stereotipler } \\
\text { ve Mesleki } \\
\text { Ayrım) }\end{array}$} & CT27 & 0,847 & \multirow{8}{*}{23,499} & \multirow{8}{*}{0,919} \\
\hline & CT35 & 0,839 & & \\
\hline & СТ30 & 0,821 & & \\
\hline & CT33 & 0,804 & & \\
\hline & CT32 & 0,753 & & \\
\hline & CT28 & 0,739 & & \\
\hline & CT29 & 0,733 & & \\
\hline & CT8 & 0,567 & & \\
\hline \multirow{10}{*}{$\begin{array}{l}\text { Örgütsel } \\
\text { Engeller } \\
\text { (Örgüt } \\
\text { Kültürü ve } \\
\text { Politikaları, } \\
\text { İnformal } \\
\text { Ağları } \\
\text { Kullanmama) }\end{array}$} & CT12 & 0,802 & \multirow{10}{*}{22,461} & \multirow{10}{*}{0,883} \\
\hline & CT17 & 0,755 & & \\
\hline & CT13 & 0,737 & & \\
\hline & CT11 & 0,736 & & \\
\hline & CT25 & 0,713 & & \\
\hline & CT19 & 0,698 & & \\
\hline & CT20 & 0,687 & & \\
\hline & CT24 & 0,631 & & \\
\hline & CT23 & 0,597 & & \\
\hline & CT21 & 0,550 & & \\
\hline Bireysel & CT2 & 0,865 & \multirow{4}{*}{14,123} & \multirow{4}{*}{0,832} \\
\hline Engeller & CT3 & 0,854 & & \\
\hline (Çoklu Rol & CT1 & 0,723 & & \\
\hline Üstlenme) & CT34 & 0,599 & & \\
\hline
\end{tabular}

Tablo 2'de görüldüğü üzere, veri faktör analizine uygundur $(\mathrm{KMO}=, 848)$. Cam tavan algıs1 toplumsal engeller, örgütsel engeller ve bireysel engeller olmak üzere 3 alt boyuttan oluşmaktadır. Varyansın $\% 60,083$ 'ü bu üç boyut tarafından açıklanmaktadır. Her üç boyutun da güvenilir olduğu görülmektedir (Cronbach's Alpha $\geq 0,70$ ).

Erillik/dişilik kültür boyutunun keşfedici faktör analizi sonucunda 5 ifadenin tek boyut altında toplandığı görülmüştür. Ölçeğin güvenilirlik katsayısı 0,881 olarak tespit edilmiştir.

Cam tavan algısının ve erillik/dişilik kültür özelliklerinin anketi cevaplayanların cinsiyet özelliklerine göre farklılık gösterip göstermediğini belirlemek üzere bağımsız gruplar $t$ testi uygulanmıştır. Sonuçlar Tablo 3'te görülmektedir.

Tablo 3. Cam Tavan ve Erillik Kültür Boyutu Algılarının Anketi Cevaplayanların Cinsiyet Özelliklerine Göre Farklılığı

\begin{tabular}{|l|l|l|l|l|l|l|}
\hline & Cinsiyet & N & Ortalama & $\begin{array}{l}\text { Standart } \\
\text { Sapma }\end{array}$ & t & $\mathrm{p}$ \\
\hline \hline $\begin{array}{l}\text { Toplumsal Engeller (Stereotipler ve } \\
\text { Mesleki Ayrım) }\end{array}$ & Kadın & 73 & 2,1607 & 0,59794 & $-4,307$ & 0,000 \\
Erkek & 49 & 1,4897 & 0,97428 & & \\
\hline $\begin{array}{l}\text { Örgütsel Engeller (Örgüt Kültürü ve } \\
\text { Politikaları, İnformal Ağları } \\
\text { Kullanmama }\end{array}$ & Kadın & 73 & 2,9388 & 0,73910 & 3,714 & 0,000 \\
\hline \multirow{2}{*}{ Bireysel Engeller } & Erkek & 49 & 3,5110 & 0,89229 & & \\
\hline \multirow{2}{*}{ Erillik } & Kadın & 73 & 2,4490 & 0,84873 & $-2,000$ & 0,048 \\
& Erkek & 49 & 2,1062 & 1,03579 & & \multirow{2}{*}{0,000} \\
\hline
\end{tabular}

Tablo 3'te görüldüğü üzere, cam tavan algıları ve erillik kültür boyutu özellikleri anketi cevaplayanların cinsiyet özelliklerine göre farkl11ık göstermektedir $(\mathrm{p}<0,05)$.

Cam tavan algısı ve erillik kültür boyutu algısının anketi cevaplayanların yaşına göre farklılık gösterip göstermediğini belirlemek üzere tek yönlü varyans analizi (ANOVA testi) uygulanmıştır. Analiz sonucunda yaşa göre anlamlı bir farklılık tespit edilmemiştir.

Cam tavan algisı ve erillik kültür boyutu algısının anketi cevaplayanların öğrenim durumuna göre farklılık gösterip göstermediğini belirlemek üzere tek yönlü varyans analizi
(ANOVA testi) uygulanmıștır. Analiz sonucunda öğrenim durumuna göre anlamlı bir farkl11lk tespit edilmemiş̧ir.

Cam tavan algisı ve erillik kültür boyutu algısının anketi cevaplayanların inşaat mühendisi veya mimar oluşlarına göre farklılık gösterip göstermediğini belirlemek üzere bağımsız gruplar $\mathrm{t}$ testi uygulanmıştır. Test sonuçları Tablo 4'te özetlenmiş̧ir. 
Tablo 4. Cam Tavan ve Erillik Kültür Boyutu Algılarının Anketi Cevaplayanların Mimar veya İnşaat Mühendisi Oluşlarına Göre Farklıllı̆g

\begin{tabular}{|c|c|c|c|c|c|c|}
\hline & Meslek & $\mathrm{N}$ & Ortalama & $\begin{array}{l}\text { Standart } \\
\text { Sapma }\end{array}$ & $\mathrm{t}$ & $\mathrm{p}$ \\
\hline $\begin{array}{l}\text { Toplumsal Engeller (Stereotipler ve } \\
\text { Mesleki Ayrım) }\end{array}$ & $\begin{array}{l}\text { Mimar } \\
\text { İnşaat } \\
\text { Mühendisi }\end{array}$ & $\begin{array}{l}68 \\
54\end{array}$ & $\begin{array}{l}1,6912 \\
1,8449\end{array}$ & $\begin{array}{l}0,81910 \\
0,85607\end{array}$ & $-1,009$ & 0,315 \\
\hline $\begin{array}{l}\text { Örgütsel Engeller (Örgüt Kültürü ve } \\
\text { Politikaları, İnformal Ağları Kullanmama }\end{array}$ & $\begin{array}{l}\text { Mimar } \\
\text { İnşaat } \\
\text { Mühendisi }\end{array}$ & $\begin{array}{l}68 \\
54\end{array}$ & $\begin{array}{l}3,3162 \\
3,2370\end{array}$ & $\begin{array}{l}0,81783 \\
0,89174\end{array}$ & 0,510 & 0,611 \\
\hline Bireysel Engeller & $\begin{array}{l}\text { Mimar } \\
\text { İnşaat } \\
\text { Mühendisi }\end{array}$ & $\begin{array}{l}68 \\
54\end{array}$ & $\begin{array}{l}2,2426 \\
2,2454\end{array}$ & $\begin{array}{l}0,90909 \\
0,98514\end{array}$ & $-0,016$ & 0,987 \\
\hline Erillik & $\begin{array}{l}\text { Mimar } \\
\text { İnşaat } \\
\text { Mühendisi }\end{array}$ & $\begin{array}{l}68 \\
54\end{array}$ & $\begin{array}{l}2,0294 \\
2,1704\end{array}$ & $\begin{array}{l}0,96089 \\
0,99159\end{array}$ & $-0,794$ & 0,429 \\
\hline
\end{tabular}

Tablo 4’te görüldüğ̈̈ üzere, cam tavan ve erillik kültür boyutu algıları anketi cevaplayanların mimar veya inşaat mühendisi oluşlarına göre farkl1lık göstermemektedir $(\mathrm{p}>0,05)$.

Cam tavan algısı ve erillik kültür boyutu algısının anketi cevaplayanların gelirine göre farkll1ık gösterip göstermediğini belirlemek üzere tek yönlü varyans analizi (ANOVA testi) uygulanmıştır. Analiz sonucunda gelire göre anlamlı bir farklılık tespit edilmemiştir.

Araştırmada kullanılan ölçeklerin, alt ölçeklerinin kendi aralarında ve birbirleriyle gösterdiği ilişkileri ortaya koyabilmek amacıyla Pearson Korelasyon analizi kullanılmıştır. Analiz sonucunda elde edilen korelasyon katsayılarına Tablo 5'de yer verilmiştir.

Tablo 5. Anketi Cevaplayanların Cam Tavan ve Erillik Alglları Arasındaki İlişkiler

\begin{tabular}{|c|c|c|c|c|c|}
\hline & & $\begin{array}{c}\text { Toplumsal } \\
\text { Faktörler }\end{array}$ & $\begin{array}{c}\text { Örgütsel } \\
\text { Faktörler }\end{array}$ & $\begin{array}{c}\text { Bireysel } \\
\text { Faktörler }\end{array}$ & Erillik \\
\hline \hline \multirow{2}{*}{$\begin{array}{c}\text { Toplumsal } \\
\text { Faktörler }\end{array}$} & $\begin{array}{c}\text { Korelasyon } \\
\text { katsay1s1 }\end{array}$ & & 0,264 & 0,521 & 0,738 \\
\cline { 2 - 6 } & $(\mathrm{p})$ & & 0,003 & 0,000 & 0,000 \\
\hline \multirow{2}{*}{$\begin{array}{c}\text { Örgütsel } \\
\text { Faktörler }\end{array}$} & $\begin{array}{c}\text { Korelasyon } \\
\text { katsay1s1 }\end{array}$ & 0,264 & & 0,081 & 0,307 \\
\cline { 2 - 6 } (p) & 0,003 & & 0,374 & 0,001 \\
\hline \multirow{2}{*}{$\begin{array}{c}\text { Bireysel } \\
\text { Faktörler }\end{array}$} & $\begin{array}{c}\text { Korelasyon } \\
\text { katsay1s1 }\end{array}$ & 0,521 & 0,081 & & 0,529 \\
\cline { 2 - 6 } (p) & 0,000 & 0,374 & & 0,000 \\
\hline \multirow{2}{*}{ Erillik } & $\begin{array}{c}\text { Korelasyon } \\
\text { katsay1s1 }\end{array}$ & $0,738^{* *}$ & 0,307 & 0,529 & \\
\cline { 2 - 6 } & $(\mathrm{p})$ & 0,000 & 0,001 & 0,000 & \\
\hline
\end{tabular}

Tablo 5'de boyutlar arasındaki korelasyonlar incelendiğinde, cam tavanın boyutlarından biri olan toplumsal faktörler ile erillik kültür boyutu algısı arasında $0,738^{\prime}$ lik pozitif bir ilişki

Elde edilen bulgular doğrultusunda araştırma hipotezlerinin bulunduğu görülmektedir.

Tablo 6. Kabul/Reddedilen Araştırma Hipotezleri

\begin{tabular}{|l|l|}
\hline Araştırma Hipotezi & Kabul/Ret \\
\hline $\mathrm{H}_{1}$ : İnşaat mühendisleri ve mimarların cam tavan algıları cinsiyete göre anlamlı bir farklılık göstermektedir. & Kabul \\
\hline $\mathrm{H}_{2}$ : İnşaat mühendisleri ve mimarların cam tavan algıları mesleğe göre anlamlı bir farklılık göstermektedir. & Ret \\
\hline $\begin{array}{l}\mathrm{H}_{3}: \text { İnşaat mühendisleri ve mimarların erillik kültür özellikleri cinsiyete göre anlamlı bir farklılık } \\
\text { göstermektedir. }\end{array}$ & Kabul \\
\hline $\begin{array}{l}\mathrm{H}_{4}: \text { İnşaat mühendisleri ve mimarların erillik kültür özellikleri mesleğe göre anlamlı bir farklılık } \\
\text { göstermektedir. }\end{array}$ & Ret \\
\hline $\begin{array}{l}\mathrm{H}_{5}: \text { İnşaat mühendisleri ve mimarların cam tavan algısı ile erillik kültür özellikleri arasında pozitif yönlü ve } \\
\text { anlamlı bir ilişki vardır. }\end{array}$ & Kabul \\
\hline
\end{tabular}




\section{Sonuçlar}

Dünya üzerinde cam tavan algıları ve erillik/dişillik kültür boyutu ile ilgili yapılan çalışmaların sonuçları incelendiğinde; birçok sektörde olduğu gibi inşaat sektöründe de kadınların mesleklerinde ilerleme kaydetmelerine rağmen halen üst düzey yöneticilik pozisyonlarında çok az pozisyon bulunduğu, kadına yönelik olumsuz tutumlara ve yaygın cinsiyet ayrımcılığına değinildiği görülmektedir.

Son yıllarda yapılan çalışmalarda cam tavan kavramı sıklıkla araştırma konusu olmuştur. Çalışanlar kariyerleri boyunca çeşitli engellerle karşılaşmaktadır. Ancak kadınların karşılaştığ daha fazladır. Karşılaşılan bu engellerin bir kısmı direkt olarak işin kendisinden kaynaklanmakta bir kısmının da sosyal nedenleri vardır. Örgütte mentor eksikliği ve erkekler arasındaki sosyal ağ, kadınların örgüt içindeki kariyerini engellerken, aynı zamanda iş-ev dengesi kaygıları ve çalışan kadınlara yönelik yaklaşımlardan da olumsuz etkilenmektedir (Gökhan, 2020).

Türk inşaat sektöründe çalışan mimarların ve inşaat mühendislerinin cam tavan algılarının erillik kültür boyutu algıları açısından belirlenmesidir. Yapılan analizler sonucunda mimarların ve inşaat mühendislerinin cam tavan algılarının oluşmasına engel teşkil eden 3 faktör bulunmaktadır. Bu faktörlerden olan toplumsal (stereotipler ve mesleki ayrım) ve bireysel engeller (çoklu rol üstlenme) boyutlarının kadınlarda erkeklere göre daha yüksek; örgütsel engeller (örgütsel kültür ve politikalar, informal ağları kullanmama) boyutunun ise erkeklerde kadınlara göre daha yüksek olduğu tespit edilmiştir. Araştırmada tespit edilen bu sonuçlar Boone vd. (2013)'nin ve Dimovski vd.'nin (2010), farklı zamanlarda yapmış oldukları araştırma sonuçları ile paraleldir. Anketi cevaplayanların erillik algılarının erkeklerde daha yüksek olduğu saptanmıştır. Diğer taraftan ankete katılım sağlayan bireylerin mimar veya inşaat mühendisi olmalarının cam tavan ve erillik kültür boyutu algıları açısından bir farklılık ortaya çıkarmadığ 1 saptanmıştır. Mimarlık ve inşaat mühendisliği alanları birbiriyle yakın ilişkiler barındıran meslek grupları olduğundan böyle bir bulguya ulaşıldığı düşünülmektedir. Yapılan literatür araştırmasında ise araştırmanın bu bulgusunu destekleyen ve karşı çıkan çalışmalara rastlanılmamıştır.

Türkiye'de inşaat sektöründe çalışan mimarların ve inşaat mühendislerinin cam tavan ve eril kültür algıları arasındaki ilişkiler incelenmiştir. Tespit edilen veriler sonucunda toplumdaki eril kültür algısı arttıkça cam tavanın boyutlarından biri olan toplumsal engeller (stereotipler ve mesleki ayrım) algısının da artacağı saptanmıştır. Elde edilen bu sonuç, kadın ve erkeğe toplum tarafindan biçilen roller ile açiklanabilir. Toplumda dişil kültürlerde cinsiyet rolleri birbirine daha yakınken, eril kültürlerde ise farklı cinsiyetler için farklı roller öngörülmektedir (Erkenekli, 2014: 578). Buna göre, dişil toplumlarda bir kadının kamyon şoförü veya hukukçu olması, bir erkeğin de balet veya ev erkeği olması normal karşılanabilmektedir. Eril kültüre sahip olan toplumlarda ise, kadın ve erkek rolleri arasında kesin bir ayrım yapılmaktadır (Hofstede 1991a: 85). Bu roller doğrultusunda eril kültür algısının artması kadın çalışanlara karşı sahip olunan önyargıları arttırabilmektedir.

Örgütlerde eril kültür algılarını azaltmak ve cam tavan engellerini kırmak için toplumsal farkındalık yaratabilmek adına toplumsal cinsiyet eşitliğini ve kadınların ön yargı ile yaklaşılan meslek gruplarında yer alması gerekliliğini vurgulayan projeler üretilmeli, cinsiyet ayrımcılığının engellenmesine yönelik gerekli yasal düzenlemeler oluşturulmalı ve uygulanmalıdır. Örgütlerde eril kültür algılarını azaltmak ve cam tavan engellerini kırmak için toplumsal farkındalık yaratabilmek adına toplumsal cinsiyet eşitliğini ve kadınların ön yargı ile yaklaşılan meslek gruplarında yer alması gerekliliğini vurgulayan projeler üretilmeli, cinsiyet ayrımcılığının engellenmesine yönelik gerekli yasal düzenlemeler oluşturulmalı ve uygulanmalıdır. Örgütler, iş-ev dengesini korumalarına yardımcı olmak için esnek çalışma saatleri sunarak kadın çalışanlara ilerleme firsatı da sunabilir. Mentorluk ve gelişim programları, kadınların ve erkeklerin eşit olarak yararlandığ Kadın çalışanlar yönetimde kendilerini geliştirmeli ve örgüt iyileştirme süreçlerini desteklemelidir (Gökhan, 2020).

Cam tavan konusunun mesleki ayrımcılığa maruz kalınabilecek meslek grupları özelinde ele alınması çalışmanın önemini ortaya koymaktadır. Bu anlamda çalışma bulguları bazı kayda değer sonuçlara işaret etse bile, gelecek araştırmalarda ele alınabilecek bazı eksiklikler bulunmaktadır. $\mathrm{Bu}$ çalışmada kesitsel bir tasarım kullanılmıştır. Gelecekteki araştırmaların, mevcut araştırmanın değişkenleri arasındaki ilişkilere zaman içindeki değişimi ortaya çıkarabilmek boylamsal tasarımlar kullanılabilir. Bu araştırmada özel sektörde çalışan 122 mimar ve inşaat mühendisine anket uygulanmıştır. Bundan sonraki araştırmalar benzer ya da farklı meslek gruplarından daha yüksek sayıda katılımcı ile yapılabilir. Sonraki araştırmalarda cam tavan algısı toplumsal cinsiyet rollerinin etkisi ve iş-yaşam dengesi gibi konular ile birlikte ele alınabilir.

\section{Kaynakça}

Altay,H. (2006). Kariyer ve Kültür: Kariyer Desteklemede Temel ve Destekleyici Fonksiyonlar: İş, Güç Endüstri İlişkileri ve İnsan Kaynakları Dergisi, 8(1).

Balasubramanian, S.A. \& Lathabhavan, R. (2018), Linking women's glass ceiling beliefs and employee satisfaction: the mediation of engagement, International Journal Human Resources Development and Management 18(1-2), 72-90.

Bendl, R. ve Schmidt, A. (2010). From 'Glass Ceilings' to 'Firewalls' — Different Metaphors for Describing Discrimination. Gender, Work and Organization, 17(5), 612634.

Boone, J., Veller, T., Nikolaeva, K., Keith, M., Kefgen, K.ve Houran, J. (2013). Rethinking a Glass Ceiling in the Hospitality Industry, Cornell Hospitality Quarterly, 54, 230-239.

Cannings, K. (1988). Managerial Promotion: The Effects of Socialization, Specialization, and Gender, ILR Review, 42(1), 77-88.

CASCIO, F. Wayne (1991). Managing Human Resource: Productivity, Quality

of Work Life and Profits (3rd ed.), New York: McGraw Hill

Channar, Z.A. (2011). Gender Discrimination in Workforce and its Impact on the Employees Pakistan, Journal of Commerce and Social Sciences, 5 (1), 177-191.

Chenevert D. and Tremblay, M. (2002). "Managerial career success in Canadian organizations: is gender a determinant?", International Journal of Human Resource Management, 13(6), pp. 920-41.

Davies-Netzley, S.A. (1998) 'Women above the glass ceiling: perceptions on corporate mobility and strategies for success', Gender \& Society, 12, pp.339-355.

Dimovski, V.; Skerlavaj, M. Man, M.M.K. (2010). Comparative Analysis Of Mid-Level Women Managers Perception Of The 
Existence Of Glass Ceiling In Singaporean And Malaysian Organizations. International Business \& Economics Research Journal (IBER), 9(8), 61-78.

Downes, M., Hemmasi, M., \& Eshgh, G. (2014). When A Perceived Glass Ceiling Impacts Organizational Commitment And Turnover Intent: The Mediating Role Of Distributive Justice, Journal of Diversity Management, 9(2), 131-146.

Dreher, G.F. (2003). Breaking the glass ceiling: The effects of sex ratios and work-life programs on female leadership at the top, Human Relations 56(5), 541-562.

Erkenekli, M. (2014). Toplumsal Kültür” Örgütsel Davranış içinde (Editörler: Ünsal Sığrı ve Sait Gürbüz), Beta, İstanbul.

Fagenson, E.A. (1989), The Mentor Advantage: Perceived Career/Job Experiences of Proteges Versus Non-Proteges, Journal of Organizational Behavior, 10 (4), 309-320.

Foley, S., Kidder, D.L. \& Powell, G.N. (2002). The Perceived Glass Ceiling and Justice Perceptions: An Investigation of Hispanic Law Associates, Journal of Management 2002 28(4). 471-496.

Goodman, J. S., Fields, D. L., \& Blum, T. C. (2003). Cracks in the Glass Ceiling. Group \& Organization Management, 28 (4), December 2003 475-501.

Gelegen, D.G. (2001). Çalışma Yaşamında Kadın Olmak, Türk Tabipleri Birliği Mesleki Sağlık ve Güvenlik Dergisi, Ocak, 27 30.

Gökhan, M. (2020). The Effects Of Glass Cellıng Perceptıon On Job Outcomes: A Research On Service Sector Employees, Yüksek Lisans Tezi, Bahçeşehir Ünversitesi,

Güney, S. (2011). Örgütsel Davranış, Nobel Akademik Yayıncılık, İstanbul.

HALAWI Ali H., "Stimuli and Effect of The Intention To Leave The Organization",European Scientific Journal, 10(10), 2014.

Hofstede, G. (1980) Cultures Consequences; Internetional Differences in Work-Related Values, Beverly Hills, C.A., Sage Publications, Beverly Hills

Hofstede, G. (1990a) Cultures and Organizations: Software of the Mind, The McGraw-Hill Book Company, London

Hofstede, G. (2010) Cultures and Organizations: Software of the Mind, The McGraw-Hill Book Company, London

Hu, T. Ve Myeong-Su, Y. (2008). "Is the Glass Ceiling Cracking? A Simple Test," IZA Discussion Papers 3518, Institute of Labor Economics (IZA).

Jackson, J.C. (2001), "Women Middle Manager's Perception of The Glass Ceiling", Women in Management Review, 16(1), 30-41.

Karcioğlu, F. ve Leblebici, Y. (2014). "Kadın Yöneticilerde Kariyer Engelleri:" Cam Tavan Sendromu" Üzerine Bir Uygulama". Ataturk University Journal Of Economics \& Administrative Sciences, 28(4).

Kelly, E. P., Young, A. O., \& Clark, L. S. (1993). Sex stereotyping in the workplace: A manager's guide. Business Horizons, 36(2), 23-29.

Knutson, B. J., \& Schmidgall, R. S. (1999). Dimensions of the Glass Ceiling in the Hospitality Industry. Cornell Hotel and Restaurant Administration Quarterly, 40(6), 64-75.

Korkmaz, H. (2016). "Yönetimde Kadın ve Cam Tavan Sendromu, Alternatif Politika Toplumsal Cinsiyet Özel Sayısı". 95-112.

Korkmaz, H. (2014). "Yönetim Kademelerinde Kadına Yönelik Cinsiyet Ayrımcılığı ve Cam Tavan Sendromu". Asos Journal(5), 1-14.

Lathabhavan, R. (2019). Glass ceiling beliefs, performance, and turnover intention through work engagement, International Journal Environment, Workplace and Employment, 5(4), 304321.

Lewis, A. E., \& Fagenson, E. A. (1995). Strategies for developing women managers: how well do they fulfil their objectives? Journal of Management Development, 14(2), 39-53.
Linehan M. (2002). "Senior female intenational managers: empirical evidence from Western Europe", International Journal of Human Resource Management, 13 (5), pp. 802-14.

Lookwood, N.R. (2004), The Glass Ceiling: Domestic and International Perspectives, Research Quarterly, Human Resource Magazine Research Quarterly, 1-49.

Luksyte, A. Ve Spitzmueller, C. (2011). Overqualified Women: What Can Be Done About This Potentially Bad Situation? Industrial and Organizational Psychology , 4, 256-259.

Meyerson, D. and Fletcher, J. (2000). "A modest manifesto for shattering the glass ceiling", Harvard Business Review, 78(1), pp. $127-40$.

Murrell, A.J. and James, E. (2001) Gender and diversity in organizations: past, present, and future directions. Sex Roles, 45(4-5), 243-57.

Ragins, B.R.; Townsend, B. \& Mattis, M. (1998). Gender gap in the executive suite: CEOs and female executives report on breaking the glass ceiling, Academy ol Management Executive, 12(1), $28-42$.

Roman, M. (2017). Relationships Between Women 's Glass Ceiling Beliefs, Career Advancement Satisfaction, and Quit Intention, Walden University, College of Social and Behavioral Sciences, doctoral dissertation.

Rudman, L.A.\& Phelan, J.E. (2008). Backlash effects for disconfirming gender stereotypes in organizations, Research in Organizational Behavior 28, 61-79.

Sabat, S.N. \& Mishra, S. (2010). Role of women in the management of police organisation: a paradigm shift, International Journal of Learning and Change, 4(4), 365-377.

Sökmen, A. \& Şahingöz, S.A. (2017). The Impact of Organizational Climate as a Glass Ceiling Reflector on Job Satisfaction and Turnover Intention of Female Employees: A Research in Hotel Operations, İşletme Araştırmaları Dergisi, 9(1), 113-133.

Stroh, L.K., Brett, J.M. \& Reilly, A.H. (1996). Family Structure, Glass Ceiling, and Traditional Explanations for the Differential Rate of Turnover of Female and Male Managers, Journal Of Vocatıonal Behavior 49, 99-118.

Schwartz, F.N. (1989). Management Women and The New Facts Of Life, Women In Management Review \& Abstracts, 4(5), 5-14.

Van Vianen, A.E.M. ve Fischer, A.H. (2002). Illuminating the glass ceiling: The role of organizational culture preferences, Journal of Occupational and Organizational Psychology, 75, 315-337.

Weyer, B. (2006). Do multi-source feedback instruments support the existence of a glass ceiling for women leaders? Women in Management Review 21(6), 441-457.

Williams, J. E., Satterwhite, R. C., \& Best, D. L. (1999). Sex Roles, 40(7/8), 513-525.

Yıldırım, M.H., Erul, E.E. ve Kelebek, P. (2014). Tükenmişlik ile işten ayrılma niyeti arasındaki ilişki banka çalışanları üzerine bir araştırma. Organizasyon ve Yönetim Bilimleri Dergisi, 6(1), 34-44. 